Artículo de reflexión

Cuestiones de Filosofía

ISSN: 0123-50-95

E-ISSN: $2389-9441$

Vol. 5 - No 24 Enero- junio, año 2019

pp. 87-108

\title{
La educación es una técnica de domesticación: una perspectiva para pensar las prácticas educativas contemporáneas
}

\section{Education is a technique for domestication: a perspective to think about contemporaneous educative practices}

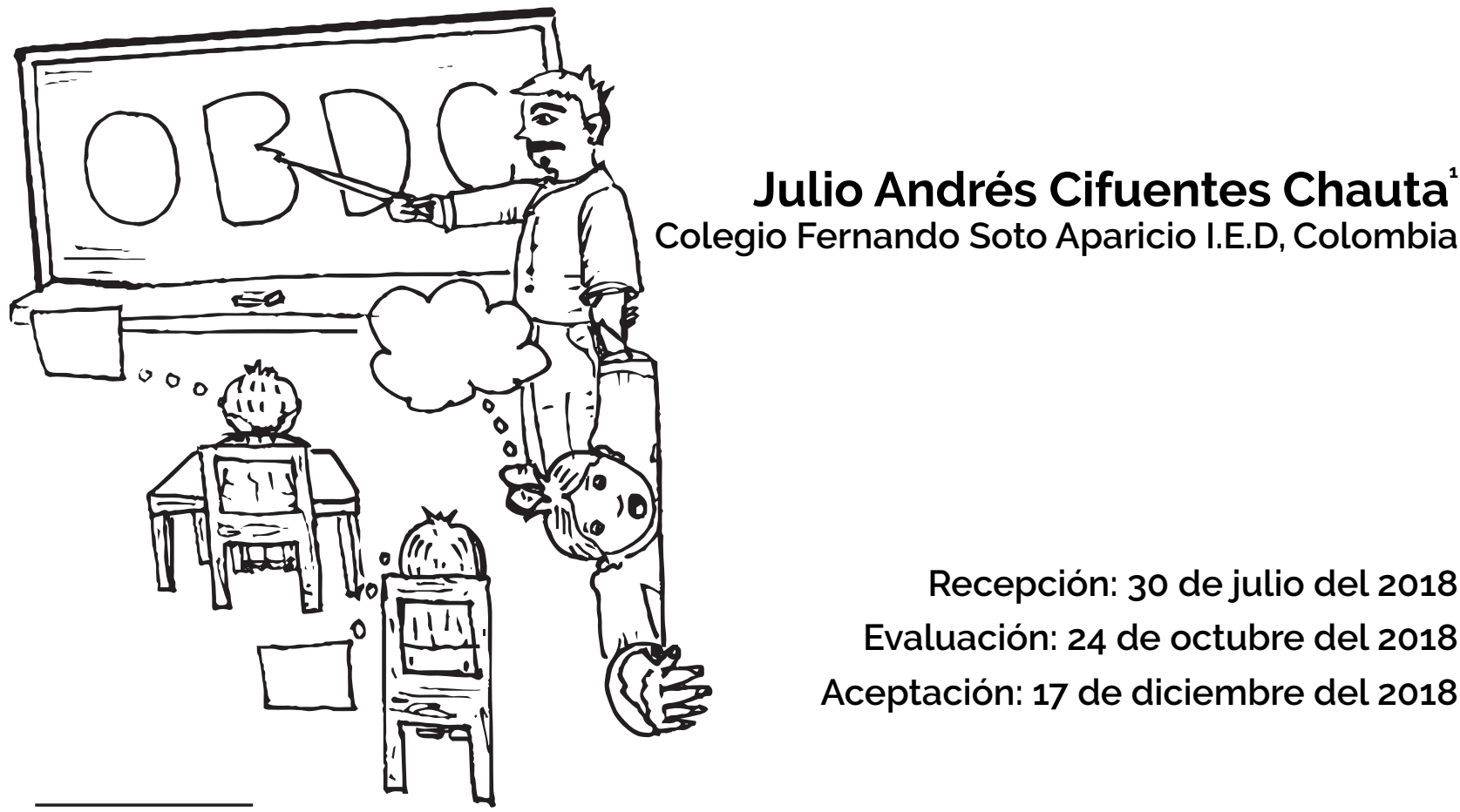

1 Docente de Filosofia y Ética y Valores del Colegio Fernando Soto Aparicio. Magíster en Filosofia de la Pontificia Universidad Javeriana y Filósofo de la Universidad Nacional de Colombia. Integrante del Nodo de Pensamiento Pedagógico Contemporáneo de la Red Distrital de Docentes Investigadores (REDDI). Este escrito es una adaptación del tercer capitulo de nuestra tesis de maestría, la cual lleva por título Hacia una ética acrobática en un mundo homeotécnico: una lectura del proyecto antropotécnico de Peter Sloterdijk. 


\section{Resumen:}

El hombre se ha alejado de sí mismo hasta el punto de entenderse en el mundo en el que vive como una cosa entre muchas otras. Ese camino errático lo ha conducido hacia guerras mundiales y civiles, masacres, exterminios, torturas y a hacer un uso inadecuado de los avances técnicos y tecnológicos. Con base en el concepto de antropotécnica de Peter Sloterdijk, este artículo sustenta, siguiendo las reflexiones de diferentes autores, que la educación es una técnica de domesticación que hace volver al hombre sobre si mismo, al permitirle procurar una mejor vida individual y colectiva. La función formativa de la educación, la fuerza del hábito y la plasticidad humana se encuentran en el centro de la historia humana y es por ello que las posibilidades de su reorientación y mejoramiento encuentran una importante cabida en las prácticas educativas. De ahí que el hábito, la costumbre y la ejercitación constituyan la base de una educación verdaderamente humanizante.

Palabras clave: antropotécnica, educación, prácticas educativas, formación humana, hábito, costumbre, ejercitación, mundo homeotécnico.

\section{Abstract:}

Humankind has separated from themselves until they perceive themselves as a thing among many others in the world in which they live. This erratic way has driven them to world and civilian wars, slaughters, exterminations, tortures, and the unappropriated usage of technical and technological advances. Based on the concept of Antropotechnique by Peter Sloterdijk, this work supports, following several authors reflections, that education is a technique for domestication that turns man against man, and thus, to allow him to search for a better individual and collective life. The formative function of education, the strength of habit, and the human plasticity are in the core of human history. For that reason, the possibilities of re-orientation and improvement find an important room in the educative practices. Therefore, habit, custom, and exercising constitute the base of a truly humanizing education.

Key-word: Anthropotechnics, education, educational practices, human formation, habit, custom, exercise, homeotechnical world. 


\section{L'éducation est une technique de domestication : une perspective pour réféchir aux pratiques pédagogiques contemporaines}

\section{Résumé :}

L'homme s'est éloigné de soi-même jusqu'au point de se voir dans le monde où it existe commel'une des choses quiy habitent. Cette erronée vision luia conduà travers de guerres mondiales et civiles, de massacres, d'exterminations et de tortures, y compris le mauvais usage des ressources techniques et technologiques. Basé sur le concept d'anthropotechnique de Peter Sloterdijk, et les réflexions d'autres auteurs, l'éducation est une technique de domestication qui a comme but faire que l'homme se détruis lui-même à travers d'une vision individualiste et collective. La fonction formatrice de l'éducation, la force des habitudes et la plasticité humaine sont au centre de l'histoire humaine et c'est pour cela que les possibilités de sa réorientation et amélioration trouvent une importante solution dans la pratique éducative. De là que l'habitude et l'exercice puissent constituer la base d'une éducation vraiment humaniste.

Mots-clés: Anthropotechnique, éducation, pratiques éducatives, formation humaine, habitude, coutume, exercice, monde homéotechnique.

\section{A educação é uma técnica de domesticação: uma perspectiva para pensar as práticas educativas contemporâneas}

\section{Resumo:}

O homem se afasta de si mesmos até o ponto de entender-se no mundo no qual vive como uma coisa entre muitas outras. Esse caminho errático conduza-o para guerras mundiais e civis, massacres, extermínios, torturas e a fazer um uso inadequado dos avanços técnicos e tecnológicos. Baseado no conceito de antropotécnica de Peter Sloterdijk, este artigo sustenta, seguindo as reflexões de diferentes autores, que a educação é uma técnica de domesticação que torna o homem sobre si mesmo, ao the permitir procurar uma vida melhor, individual e coletiva. A função formativa da educação, a forma do habito e a plasticidade humana se encontram no centro da história humana e, por isso, as possibilidades de sua reorientação e melhoramento encontram um lugar importante nas práticas educacionais. Dai que o habito, a costume e a exercitação constituíam a base de uma educação verdadeiramente humanizam-te.

Palavras chave: antropotécnica, educação, práticas educacionais, formação humana, habito, costume, exercitação, mundo homeotécnico. 


\section{Introducción}

Vivimos en tiempos apocalipticos en los que la complejidad de lo que ocurre a diario exige que los pensadores contemporáneos repiensen la historia humana y orienten el camino del hombre hacia sí mismo. Una época marcada por masacres, guerras, injusticias sociales, profundos cambios religiosos y políticos, desastres naturales, alteraciones climáticas producto del calentamiento global y desarrollos científicos y tecnológicos de avanzada aplicados en todos los ámbitos de la vida humana. Una época donde lo monstruoso de la violencia humana, que genera desolación y muerte por doquier, va de la mano del potencial ultra desarrollado de la inteligencia humana, que produce expectativa y vida donde se impone. No es, sin embargo, un fatalismo epocal aislado, pues

la historia no se dispone a cerrar el círculo, queda presa junto con la sociedad movida por la tecnología, en una dinámica que Heidegger llama el «errar». Ello caracteriza a la forma histórica de moverse la existencia que no está «consigo» y se abre paso a través de lo no-propio, sea con el objetivo devolver finalmente a casa, sea en el modo del viaje interminable sin destino. Tanto en el errar dirigido como en el no dirigido, la dispersión y la apatricidad preceden a la reunión y el regreso a la patria; los yerros son empíricamente la norma en la aprehensión de sí mismo (Sloterdijk, 2011, p. 140)2.

Con el derrumbe de la metafísica clásica, que se basa en una ontología monovalente y una lógica bivalente, y la pérdida de influencia del humanismo ilustrado en nuestro tiempo, ese continuo errar humano de dominación y cosificación de todo lo existente parece estar llegando a su final, ya que se abre una profunda transformación en la comprensión del hombre y una creciente esperanza en que por fin este pueda encontrar su verdadera humanitas. De esta manera, Sloterdijk (2011) considera el pesimismo de Heidegger -presente en su interpretación del curso del mundo como "un errar permanente y sin regreso"- como altamente sospechoso y equivocado.

2 El entrecomillado «...» que aparece en los textos citados corresponde a las ediciones tomadas como referencias en el presente escrito. El traductor conserva del original este recurso estilistico para resaltar términos que son fundamentales para el autor. 
En su opinión, la conducción actual del actuar humano mediante el influjo de la técnica, contrariamente a lo que se piensa, lleva a que el hombre se defina como el hacedor desbordante e insuperable que jamás haya existido sobre el globo terráqueo. En efecto, es el hombre moderno el que se atreve a preguntar sin más "si lo que él puede hacer y hace es también realmente a si mismo y si en este hacer está consigo mismo" (2011, p. 140). Donde solamente hay fatalidad y pesimismo, nuestro filósofo ve un camino que llevaria indiscutiblemente al hombre contemporáneo a volver hacia sí mismo, a integrar su exterioridad en el yo, y a buscar en su historia natural y social de producción la clave que le lleve de regreso (2011, p. 145).

Sloterdijk piensa en la historia no-errática del hombre en virtud de la plasticidad que le es propia. El hombre no es un ser acabado, estático, sino el resultado de ciertas operaciones técnicas, entre las que cabe anotar la educación, en tanto su fin último es la formación y el perfeccionamiento humano, como lo señala Flórez y Vivas (2007). Entender la acción educativa como antropotécnica nos permite, como defenderemos en el presente trabajo de reflexión, albergar la esperanza de que el hombre esté de nuevo consigo mismo, al implicar prácticas que procuren un mejor modo de vida en un mundo racional, con lo cual cabria la posibilidad de contrarrestar eficazmente la violencia propia del ser humano y aceptar los avances tecnológicos y genéticos como realmente benéficos para la humanidad.

Para ello, en primer lugar, vamos a determinar cuál es la descripción de la naturaleza humana que nos permite albergar la posibilidad de corregir y construir una historia no-errática. En segundo lugar, mostraremos que hacer una lectura antropotécnica de la educación, en la que el hábito sea el mecanismo para modificar la conducta humana, lleva a que el hombre vuelva consigo mismo. En tercer lugar, pondremos de relieve que la teoría general del ejercicio de Peter Sloterdijk es en últimas lo que le da sentido a la labor formativa de la educación. Y, en cuarto lugar, a modo de conclusión, precisaremos que la procura de una mejor vida basada en la ejercitación es lo que debe conducir las prácticas educativas del profesorado contemporáneo.

\section{La naturaleza humana: tendencia bélica y plasticidad}

Agamben sostiene que lo que caracteriza a la política moderna no es la inclusión de la vida en la política y el hecho de que ésta se haya convertido en su centro, sino 
más bien el proceso histórico que, de manera progresiva, fue haciendo coincidir el espacio de la nuda vida -que originariamente estuvo situado al margen del orden jurídico- con el espacio político, hasta el punto de entrar en una zona de irreductible indiferenciación (1998, pp. 18-19). Esta inclusión de la nuda vida en el espacio político puede representarse no tanto como el objeto de la política, sino como algo que está latente en ella y que solo excepcionalmente llega a ser objeto directo.

El momento privilegiado del alcance universal de la biopolítica son los campos de exterminio nazi. Agamben aborda este asunto en Lo que queda de Auschwitz, lugar en que, dentro del espacio jurídico de un Estado y al mismo tiempo fuera de él, la vida es tratada como materia sin forma humana. Esta circunstancia límite, y singular por sus caracteristicas, somete a una dura prueba todos los referentes éticos y políticos válidos hasta ese momento, e incluso el concepto mismo de hombre. Los hechos alli ocurridos son de tal envergadura que ambos asuntos son de difícil tratamiento, pero al mismo tiempo ineludibles. Es posible que las palabras no logren en modo alguno referir lo que sucedió realmente en Auschwitz, por lo que su verdadera comprensión escapa inevitablemente a nuestra propia capacidad mental.

Auschwitz es la llamada 'zona gris', que Agamben describe como el lugar de lo humano -o, mejor aún, de lo demasiado humano- donde no importa en qué lado se esté, pues los limites entre el verdugo y la víctima no están bien definidos. Ambos son igualmente innobles, cada uno de ellos comparte una única y despreciable miseria humana. Por eso, en palabras de Agamben, este lugar no es más que el lugar donde se manifiesta en todo su esplendor la banalidad del mal (2000, p. 20). El que en esta zona lo jurídico deba ser trascendido no significa que los culpables no deban comparecer ante un tribunal para pagar por lo que hicieron, sino que lo sucedido en Auschwitz exige repensar al hombre en un nuevo paradigma ético-político.

Toda esta atrocidad, que es motivo de vergüenza para la humanidad entera, no puede quedar en la impunidad y mucho menos ser tratada como un mero hecho excepcional. Auschwitz es la manifestación violenta más significativa llevada hasta sus últimas consecuencias que el hombre ha sido capaz de perpetrar contra sí mismo. La tendencia bélica es al parecer un rasgo de nuestra naturaleza humana. Asi lo expone Hobbes (1992) cuando en su Leviatán sentencia célebremente que el hombre en el estado de naturaleza es un lobo para el propio hombre. En su opinión, la violencia le es propia, pues 
durante el tiempo en que los hombres viven sin un poder común que los atemorice a todos, se hallan en la condición o estado que se denomina guerra; una guerra tal que es la de todos contra todos. Porque la guerra no consiste solo en batallar, en el acto de luchar, sino que se da durante el lapso de tiempo en que la voluntad de luchar se manifiesta de modo suficiente... la naturaleza de la guerra consiste no ya en la lucha actual, sino en la disposición manifiesta a ella durante todo el tiempo en que no hay seguridad de lo contrario. Todo el resto de tiempo es de paz (Hobbes, 1992, p. 102).

Contrariamente a este postulado, como sostiene Dewey (2014), en realidad la guerra no es producto de la tendencia bélica del hombre sino de las condiciones sociales, políticas y económicas en que viven los pueblos, las tribus, las ciudades y naciones concretas. Aunque esta nueva perspectiva en modo alguno promete que la guerra vaya a ser abolida algún día, logra desplazar el problema hacia dimensiones más esperanzadoras. Que la violencia o las guerras no se basen en lo originariamente inmutable de la constitución humana, abre la puerta a que, como lo señala Dewey, "los indestructibles impulsos que en las guerras se utilizan sean susceptibles de canalizarse hacia muchos otros fines" (2014, p. 129); esto es, a que la tendencia bélica que agrupa múltiples impulsos congénitos sea corregida, redistribuida, desviada y controlada, lo que impediria la guerra.

En suma, si bien es cierto que la tendencia bélica que hace parte de la naturaleza humana no fue la que trajo consigo a Auschwitz ni produce las guerras, y puede con todo ser canalizada, es lícito suponer que la conducta humana puede ser modificada hacia fines buenos y socialmente beneficiosos.

Esa posibilidad de modificación de la conducta humana no puede entenderse como un hallazgo aislado o excepcional, pues simplemente pone de manifiesto la plasticidad como lo propio de la naturaleza humana. Para Peter Sloterdijk (2012), el hombre es un producto, el resultado sobre si de ciertas operaciones técnicas que denomina antropotécnicas. En su tarea de establecer la verdadera condición actual del ser humano, encuentra que su dramático 'venir-al-mundo' tiene una historia muy particular, compuesta por dos tipos de relatos muy diferentes entre sí: uno de índole natural y otro de índole cultural. En estos relatos, el hombre es presentado como el resultado de prolongados procesos de formación e innegables producciones suyas, 
siéndole imposible, conforme a su propia esencia, darse en cuanto tal en la pura naturaleza. Su 'aparecer' en el mundo, en contra de lo afirmado por Heidegger, ha de entenderse como una situación tecnógena, en la que confluyen aspectos de diversa índole.

Lo primero que hay que resaltar de esa historia es que es interpretada por nuestro filósofo como aquel precipitarse de manera prematura del homínido fuera del medio ambiente en el que habitaba, tras fallar en su esfuerzo por ser y permanecer siendo un animal. Se trataría, pues, del relato del hiper-nacimiento del hombre, de la consideración del paso que el pre-humano tuvo que dar para dejar de ser un lactante y llegar a convertirseen un mundante. Al ganar ontológicamente el mundo, el pre-humano encontró no solo la forma de satisfacer sus propias necesidades en ese medio en el que vivía y que le resultaba realmente hostil y peligroso, dada su innegable desventaja e inmadurez natural frente a los demás animales, sino también lo que lo catapultaria decisivamente en esa inevitable carrera hacia lo que debería llegar a ser un día: un homo sapiens.

Fueron cuatro mecanismos los que hicieron posible el surgimiento del hombre, los cuales, a pesar de ser muy distintos entre sí, forman una única estructura que se desarrolló -y que todavía se sigue desarrollando- a partir de causalidades circulares de carácter antropotécnico. Como sostiene el mismo Sloterdijk, la reflexión sobre el hombre y su posibilitación histórica debe entonces girar siempre en circulo, de modo que podamos volver una y otra vez al punto de partida: el éxtasis existencial. Este no debe ser abandonado jamás, por cuanto es lo que en nuestro tiempo nos permite sumergir en esa apertura radicalizada que constituye nuestra conditio humana (2011. p. 102).

Ahora bien, los mecanismos son los siguientes: "el mecanismo de la insulación, el mecanismo de la exclusión corporal, el mecanismo de la pedomorfosis o de la neotenia, con que se designa la progresiva infantilización y el retardo de las formas corporales, y el mecanismo de la transferencia, que explica cómo el hombre pudo estar «de camino hacia el lenguaje»" (2011, p. 114). Heidegger también lo señala de manera reiterativa, dado que 'este estar de camino' es, además, 'una forma de ser con otros'.

Con base en lo anterior, encontramos entonces que la naturaleza humana no solo es tendencia bélica sino también plasticidad, lo cual lleva a pensarla como algo 
modificable, así como el mundo que habita. Pues este es ante todo el recinto que el hombre produjo y consolidó a través del uso de medios técnicos, tanto de los elementales como de los refinados, para distanciarse del circunmundo y crear así un clima favorable similar al del útero materno. Respecto de la naturaleza humana, por tanto, nada es definitivo, inmutable, sino cambiable y mejorable, siempre y cuando se apliquen técnicas deshinibidoras o inhibidoras adecuadas. Y, sobre todo, en tanto hay una tendencia natural del hombre a conservar los lujos psicosomáticos que produjo en su proceso de hominización y que perduran en el tiempo. Se procura siempre de manera originaria una vida lujosa y de confort, a la que sin importar el modo, la defiende como su producción más ingeniosa e importante.

\section{La educación como antropotécnica: formación, costumbre y ejercitación}

Con el fin de seguir manteniendo una vida de confort en el mundo que ha producido técnicamente el hombre, este se ve abocado a desarrollar ciertas prácticas inmunológicas. Ellas son fundamentalmente técnicas de inmunización que apuntan en dos direcciones: una a la producción de unos hombres por otros, con el fin de propiciar un interior afable y confortable para las comunidades residentes y desde ahi contrarrestar la amenaza constante de los agresores externos; son las llamadas técnicas para dejarse operar. La otra tiene que ver con la producción de hombres a partir de si mismos, con el fin de hacer frente al destino y los avatares propios de la vida; son las llamadas técnicas de autooperación. En ambos casos, se busca modificar y optimizar técnicamente el comportamiento humano para garantizar un ambiente favorable y benéfico para todos.

El primer tipo de prácticas merece especial atención, por cuanto pone de manifiesto la importancia que tiene la crianza en los seres humanos. Al final de su polémica conferencia "Normas para el parque humano", Sloterdijk (2011) presenta un problema en relación con las disposiciones que se deben tomar frente al comportamiento de los hombres que habitan en comunidad: saber qué programa de domesticación yqué potencia domesticadora ha de elegirse para que el efecto invernadero perdure y sea cada vez más afable. El proceso de culturización que se deduce del ser sedentario implica asi un mecanismo permanente de selección. Las formas específicas de comportamiento social que se requieren son establecidas a partir de relaciones 
jerárquicas de poder, en las que se tiene la potestad y la obligación de inhibir aquellos comportamientos que se consideran peligrosos para el grupo, a la vez que desinhibir aquellos que se consideren beneficiosos. 'Inhibición y desinhibición', como muy bien lo señala Castro, son "los filtros artificiales de selección que hacen posible la crianza de un ser capaz de vivir civilizadamente" (2012, p. 68).

El lugar común de decisión y selección aparece ya señalado por Nietzsche en uno de sus textos clásicos de Asi habló Zaratustra: aquel en el que el profeta vuelve a su pueblo y encuentra que en este el hombre se iba volviendo cada vez más diminuto, en razón de la resignación que había impulsado a sus lugareños a abrazar una pequeña felicidad y a aceptar como doctrina fundamental que "la virtud es para ellos lo que vuelve modesto y manso: con lo que el lobose ha convertido en perro, y el hombre mismo en el mejor animal doméstico del hombre" (1993, p. 240).

Según Sloterdijk, Nietzsche busca poner de relieve lo retorcidos e imbricados que pueden llegar a ser los procesos en torno a los cuales giran los diferentes intentos de producción humana. En sus sentencias, deja al descubierto lo que la tradición humanista ocultaba detrás de su pretendida inocencia y carácter inofensivo, y que desde ese entonces nadie puede atreverse hoy a negar: las duras luchas que deben librarse "en torno al derecho de la crianza humana y en torno a los diferentes intentos por monopolizarlo o gestionarlo" (Quintanas, 2009, p. 164).

Este conflicto entre los criadores del hombre, y que atañe directamente a las orientaciones sobre la recta crianza, no podía en modo alguno develarse desde el humanismo mismo, pues este solo podía apuntar a lo que concierne a los medios requeridos e indispensables para domesticar, adiestrar y educar, y que se ligaban uno a uno con las actividades de leer, estar sentado y amansar, sin entrar a cuestionar jamás el concepto mismo de 'hombre' (Sloterdijk, 2011, p. 221). Es la disputa, en últimas, que en términos nietzscheanos se presenta entre los criadores del hombre que buscan empequeñecerlo y los que buscan engrandecerlo.

Del hecho de que originariamente "los hombres son aquellos animales de los cuales unos crian a sus semejantes, mientras que los otros son los criados" (Sloterdijk, 2011, p. 215), se sigue que la educación puede leerse en clave antropotécnica. 
Los propósitos de la educación, si bien se han circunscrito tradicionalmente a la instrucción y su consabida generación de aprendizajes, trascienden la formación humana. Así lo señalan Flórez y Vivas cuando afirman que "la formación aparece como una constante reconocida por pedagogos, desde Juan Amós Comenio hasta nuestros dias, consistente en esperar de la educación la formación de las nuevas generaciones, como un proceso de humanización que conduce a niveles superiores de autonomía, inteligencia y solidaridad" (2007, p. 166).

Podríamos entonces decir que la formación ha de ser el fin perdurable de la educación, lo que queda, lo que le da sentido. Formarnos como seres humanos, en concordancia con lo que somos, debe ser la tarea principal de todo acto educativo, pues

la condición de la existencia humana es formarse, integrarse, convertirse en un ser espiritual capaz de romper con lo inmediato y lo particular, y ascender a la universalidad mediante el trabajo compartido y la reflexión filosófica sobre sus propias raices. Formar a un individuo es facilitarle que asuma, en su vida, su propia dirección racional, reconociendo a los otros el mismo derecho y la misma dignidad (Flórez y Vivas, 2007, p. 166).

Así, la formación pone de manifiesto esa interacción humana que se cuestiona por cómo uno debe conducir al otro para desarrollar armónicamente sus múltiples dimensiones en beneficio de todos y de la autorrealización propia. No es una tarea simple, sino compleja: el selector debe proporcionar una serie de reglas racionales que en modo alguno trasgredan al que se educa, sino que le potencialicen todas sus habilidades y conocimientos y procuren el bien de la comunidad.

La educación, en consecuencia, debe proveer de prácticas inhibidoras y deshinibidoras a las sociedades, a fin de que formen al hombre, lo domestiquen, lo mejoren. Como lo recalca Noguera-Ramirez, "en el centro de la paideia está la preocupación por la virtud, por la areté como posibilidad de perfeccionamiento de los hombres" (2017, p. 26). En este momento, surge la siguiente pregunta: ¿cómo deben ser esas prácticas educativas para que lleven al hombre a niveles superiores de humanización?, o con mayor profundidad, ¿qué hace del todo posible la formación 
humana cuando en nuestra naturaleza hay tendencias, impulsos y costumbres tan arraigadas que en lugar de ser facilitadores son en realidad obstáculos para este propósito humanizante?

En la definición de formación encontramos una pista para solucionar esas cuestiones. Siguiendo a Runge-Peña, con ese término lo que se quiere significar es "la cultura interiorizada por un individuo que, en ese proceso de interiorización, resignifica y redimensionaliza dicha cultura -la tradición- y con ello se hace, a su vez, sujeto, portador y expresión de aquella" (2012, p. 249). Es decir, la formación es ante todo hábito, costumbre, repetición, afectación de la vida personal y social. Por tanto, para que una conducta pueda ser modificada en elproceso formativo se requiere de otra conducta que la contrarreste. Así lo deja entrever Dewey cuando afirma que "en mayor medida las costumbres subsisten porque los individuos forman sus hábitos personales bajo condiciones establecidas por hábitos anteriores" (2014, p. 72). La fuerza de la costumbre le es inherente, por ende, a la educación. Al pretender la mejora humana, la educación debe procurarse ciertas prácticas educativas que impongan nuevas conductas e ideales con base en antiguas conductas validadas socialmente.

Las costumbres se producen cuando los grupos sociales interactúan y establecen lazos identitarios. Son esas asociaciones humanas las que, en consecuencia, pueden modificar las costumbres individuales de aquellos que pertenecen a ellas direccionándolas hacia otras nuevas, y lo hacen en virtud de hechos de acción concreta. No puede haber resistencia en ello, por cuanto el hombre es un ser que al nacer está en completa indefensión y establece lazos de dependencia para poder sobrevivir. Es decir, la efectividad de la educación como mecanismo de modificación de la conducta humana radica en que las costumbres se forman con base en necesidades humanas concretas y la pertenencia del hombre a instituciones sociales. Asi lo deja ver Dewey (2014) al señalar que "las diferentes costumbres, los arreglos interactuantes establecidos, forman y fomentan mentes diferentes" (p. 76).

De este modo, las prácticas educativas ${ }^{3}$ tendientes a la mejora del hombre deben constituirse en costumbres, en mecanismos de acción arraigados. La forma de

3 Entendidas como "prácticas que constituyen, median, regulan y modifican la experiencia que las personas tienen de si mismas, su experiencia de sí y las formas como cada persona se conduce a sí misma y acepta ser conducida o conducir a los otros" (Marín-Díaz, 2017, p. 62). 
activarlos consiste en mostrarle al hombre los resultados favorables o desfavorables de su actividad. Esto bajo la premisa de que la calificación es un tipo de refinamiento que se usa para influir sobre el carácter y el comportamiento humano. Al respecto dice Dewey que

no hay que proporcionarle al hombre incentivos para su actividad en general, pero si es necesario, y mucho, inducirlo a guiar sus propios actos por medio de una inteligente percepción de sus resultados ya que, a la larga, ésta es la forma más efectiva de influir sobre la actividad para que tome la dirección conveniente y no la objetable (2014, p. 137).

Esas prácticas solo pueden llegar a constituirse en mecanismos de acción a través de una continua ejercitación al modo de los artistas, quienes, para adquirir y desarrollar una destreza, deben ejercitarse continuamente, sin desfallecer, hasta volverla casi que rutinaria. Su arte está dado en virtud de la repetición diaria. En la naturaleza misma de la repetición, si se siguen ciertas reglas específicas, se encuentra la clave de su propia superación. Como la repetición no es solo pasividad (repetición repetida), sino también actividad (repetición que hace repeticiones), es claro que para contrarrestar las fuerzas inertes de lo habitual inicial solo basta con servirse de ellas para poder superarlas.

\section{La teoría general del ejercicio: plenitud de la educación}

Considerar la educación como antropotécnica, a partir de su función formativa, solo nos ha permitido caracterizar las prácticas educativas como mecanismos de acción conducentes a alcanzar una humanización superior. Sin embargo, la mejora humana puesta como fin educativo adolece aún de precisión y corre un riesgo si no se le limita lo suficiente. Dicho riesgo es generar un nuevo despotismo ilustrado o un estado eugenésico. Al respecto, Sloterdijk nos advierte que ir en contra de las incursiones genéticas en el ámbito humano, al considerar que con ello se impide que el hombre se apropie de su mundo como debe ser e integre lo exterior a su propio yo, es desde todo punto de vista improcedente y contradictorio con esto mismo que pretenden. Esto en razón de que llevan a que el yo se sumerja en lo cósico y se pierda ahí, con lo que se olvida que el hombre "no es una instancia que deba, o pueda, elegir estar enteramente consigo mismo y estar fuera de sí mismo" (2011, p. 145). 
Pensar el homo humanus es disponer la humanitas en relación con el estado de la técnica, por lo cual dicha oposición solo puede llevar al hombre actual a alejarse de su propia autocomprensión y perderse en el camino que lo regresa a sí. Cuanto mayor sea el avance técnico, mayor debe ser la propia autocomprensión del hombre, pues la incubadora humana "es producida por las técnicas de los medios contundentes y climatizada por las técnicas de los medios blandos" (2011, p. 146). En consecuencia, no hay motivo para temer que el ser humano sea sometido en el futuro a innovaciones y manipulaciones. Antes fueron instituciones como la Iglesia y la escuela las que llevaron a cabo este proceso, ahora es el turno de las tecnologías genéticas. La evolución humana implica una transformación autotécnica hacia el confort y el lujo, sin que en ello haya algo perverso o contradictorio. Por esta evolución, nos dice Sloterdijk, "sigue siendo la plasticidad una realidad fundamental y una tarea ineludible" (2011, p. 147).

Para evitarquehayauna desproporción irracionalen lasoperaciones antropoplásticas y que pueda surgir un mecanismo que procure el bienestar de la humanidad y conduzca al hombre de vuelta a si, es necesario que se impida que el saber y el poder hacer, que marcan el destino de nuestro tiempo, sean puestos al servicio de la tendencia egoísta y bélica que le es natural al ser humano; de no hacerlo, se alzarian pueblos contra pueblos en guerras catastróficas para la humanidad tras el uso de armamento biológico y atómico. Lo que, sin lugar a dudas, ocasionaría que el mundo de las cosas se viera abocado a una nueva esclavitud ontológica.

La manera de hacerlo es produciendo un mundo homeotécnico cuya naturaleza esté dada por el respeto a las cosas, bajo el precepto de que "las cosas son o pueden llegar a ser por si mismas". De igual forma, que tenga "un carácter más de cooperación que de dominio, incluso en las relaciones asimétricas" (2011, p. 148). En un mundo asi entendido, cualquier manipulación que se haga sobre las cosas o el hombre mismo debe desarrollarse en virtud de la máxima idoneidad de estas o este, con lo que la técnica adquirirá un carácter positivo en la mejora de uno mismo y del entorno también.

A pesar de ello, y de que fácilmente se puede asociar a la tecnología con la perversión humana, como lo ha demostrado la historia europea reciente, Sloterdijk 
confía en que un mundo homeotécnico, que ya empezó a forjarse en civilizaciones tecnológicas y comunicativamente más avanzadas, sea del todo una realidad en el futuro. Incluso, se atreve a conjeturar que la complejidad de las cosas mismas lleva a que las perversiones alotécnicas del pasado no afectarán en modo alguno el dominio homeotécnico.

Por eso, Sloterdijk encuentra en el pensamiento homeotécnico la posibilidad de crear una ética de las relaciones que no sea hostil y dominadora. El énfasis de esta ética -más que en la cosificación u objetivación de lo otro- radicará en las condiciones internas de lo que tiene en frente y que coexiste con él. Aunque, quizás, lo que más seguro le lleva a estar a nuestro filósofo de la existencia de un mundo inteligente es la creencia de que un mundo globalizado como el nuestro no admite apariciones tiránicas, tan solo teorias y sucesos que pueden traer algún tipo de beneficio a la humanidad misma. En este mundo se acepta y premia a los que trabajan mancomunadamente, a los que promocionan y propenden hacia el bienestar común.

Una civilización homeotécnica es, entonces, un primer paso y la condición necesaria para que un nuevo estado de cosas se instaure en nuestro tiempo y en la que una ética del bienestar sea la que rija los destinos de los hombres y de las naciones. Pues lleva a que la historia del errar mengue considerablemente y que en su lugar se formen procesos de liberación real y aumenten los enlaces positivos, que llevarán al hombre a encontrarse consigo mismo y a aceptar como benéfico solo aquello que demuestre serlo en generaciones futuras. En este contexto polivalente, colaborativo y pluralista es que Sloterdijk se atreve a prefigurar una teoría general del ejercicio, de efectos no solo beneficiosos para los hombres que logren autosuperarse a sí mismos, sino también para las civilizaciones que se inmunicen a partir de estos hombres.

En la primera parte de su libro Has de cambiar tu vida, Sloterdijk (2012) nos presenta el programa de ejercicios que deben seguir los hombres pertenecientes a la alta cultura para conquistar lo improbable y dejar atrás definitivamente los campamentos de base, esos en los que la fuerza de la costumbre arruina todo e inmoviliza el actuar humano. El punto central de este programa está así enfocado en el paso que esos 
arriesgados hombres dan hacia el monte de lo improbable, en la medida que es ahí donde tiene lugar el ímpetu que lleva a esos hombres a lo que está por encima de lo ordinario, a la ruptura de lo habitual, al surgimiento de un nuevo ser que es capaz de hacerse cada vez mejor al catapultarse a sí mismo desde su propio interior. A ese programa de ejercicios, Sloterdijk lo denomina, sin más, programa ético. Como este implica una clara alusión a dos virtudes propias de los atletas (el amor al honor y el amor al esfuerzo), Sloterdijk no duda en presentarlo como el arte de la ascética y la acrobacia.

Una ética acrobática como esa deberá responder, sin lugar a dudas, a la pregunta de cómo "el pensamiento de lo que trasciende lo habitual pudo adueñarse de ciertos individuos señalados", para indicar luego el camino que deben seguir los demás residentes -de cualquier campamento de base regido por los hábitos-con el fin de escalar la cima del perfeccionamiento humano al modo de aquéllos (2012, p. 248).

Una cima que, una vez alcanzada, tiene la particularidad de instar al hombre de la alta cultura a seguir escalando cumbres cada vez más altas y a no querer regresar jamás de donde partió. Es, por tanto, un ser escindido entre lo que es y lo que fue, un ser reubicado junto a su sí mismo (un si verdadero y auténtico), un ser capaz de mirar hacia atrás sin nostalgia de lo que dejó y, en adelante, con la mirada puesta en la cumbre próxima por escalar. Esto es del todo posible si, como asegura Sloterdijk, se asume una teoría del habitus como entrenamiento virtuoso -al mejor estilo de Aristóteles y Santo Tomás de Aquino- que allane el camino para una teoría general de la antropotécnica, ya que lo fundamental es saber cómo es que el sujeto humano se configura eficientemente mediante "el ejercicio, el entrenamiento y la habituación" (2012, p. 238).

La función de la costumbre seria hacer normal y fácil lo que de otra forma no podría serlo, al ayudar a que se conserven nuestras capacidades constituidas y a que se abra la posibilidad de que sigan creciendo con nuevas adquisiciones. Su fuerza residiria en hacer de la consecución de 'lo bueno y valioso en si' un logro admirable y fácil de alcanzar. $Y$ es en este punto en el que Sloterdijk vislumbra el inicio de una teoría general del ejercicio, pues solo mediante un permanente ejercicio será posible remover poco a poco la improbabilidad de lo bueno, lo que hace parecer esto 
como una actividad sencilla. Por tanto, quien se ejercite adecuadamente habrá ganado a la improbabilidad del bien y hará que ser virtuoso sea una condición humana espontánea y natural, gracias a la cual el ejercitado podrá mantenerse en lo alto como un acróbata de la virtud, expuesto siempre al peligro, al riesgo de la innovación y a la búsqueda de alturas cada vez más altas.

Lo anterior nos sumerge en el campo de la educación, dado que nos interpela a salir hacia la conquista de lo beneficioso, lo virtuoso y lo excelso. Eso es lo que se debe entender por la mejora de sí mismo. Cuando el hombre da el crucial paso hacia la cima, nada hay que lo detenga y lo haga devolver. Su cambio de vida empieza tan pronto como es consciente de la naturaleza habitual del comportamiento humano y empieza a configurar una nueva forma de vida, con un lenguaje propio y unas actitudes nuevas, frente a su estar y su conducirse en el mundo. Una vez dado el paso, no hay marcha atrás, ya que considera que vivir pegado a los malos hábitos no es vivir verdaderamente; considera, además, que no se puede vivir con lo que es ajeno a la vida interior $y$, mucho menos, vivir subyugado a ello.

En este contexto, es claro que este nuevo hombre no deja de estar poseído por el daimon de dos caras, sino que gracias a su nuevo programa de entrenamiento convierte las pasiones y las costumbres en disposiciones manejables y mejorables. Asi pues, los antiguos filósofos y pedagogos -que advirtieron la producción de un nuevo arte de maniobrar la vida o ejercitación- se convierten en modelo para que los formadores actuales sean esos observadores capaces de forjar un nuevo futuro, de señalar el camino a los otros para ir por encima de lo habitualmente cosificado.

Esta nueva cultura del ejercicio pone a la cabeza nuevas figuras modélicas de la espiritualidad: los sabios, los atletas y los maestros en general. Con esto se comienza a perfilar el horizonte que han de seguir las nuevas generaciones que se quieran ejercitar contra las inercias de las culturas heredadas y el influjo perturbador de las emociones. Unas nuevas generaciones llamadas a convertirse en verdaderos ascetas y acróbatas: hombres, que por su empeño de clarificación y de ejercicio, hagan del imperativo iHas de cambiar tu vida! su principal norma de conducta. La idea es que se configuren a sí mismos como seres superiores a su vida pasional, a su vida de hábitos y a su vida de representaciones. Es una tarea ardua que deben 
asumir esos docentes que propendan hacia un mundo cada vez más humanizante.

Para Sloterdijk, por tanto, esta transformación no tiene que ver en absoluto con un cambio de creencias por otro, sino, ante todo, con la salida de un modo de vida pasivo a un modo de vida activo, en el que la actividad ascética es incesante e imprescindible. Sentadas asi las cosas, ese nuevo mundo en donde habitan las élites superiores y la alta cultura ha de ser denominado, siguiendo a Nietzsche, el astro de las acrobacias, por cuanto sus habitantes, gracias a su continuo ejercitarse a un nivel superior, estarán siempre sujetos a la tensión propia del acróbata, que hará aparecer lo difícil como fácil y la práctica de lo imposible como algo normalizado sin el más mínimo esfuerzo (2012, p. 254).

La mayor conquista que debe alcanzar el hombre en el ámbito de lo improbable es el sometimiento de la tiranía de la muerte, pues esta es la que en gran medida lo empuja hacia la pasividad absoluta. Quien logre arrojarse a la muerte, para integrarla al dominio de sus capacidades, habrá mostrado que dentro de las posibilidades humanas está el superar lo insuperable o identificarse con lo más amenazante para la supervivencia de la humanidad.

Para ello, el hombre debe iniciar una serie de entrenamientos muy duros, ya sea mediante la ayuda de esfuerzos ascéticos que conduzcan a una actitud de poder morir dignamente (al modo de la escena de la muerte de Sócrates), o mediante la conducción de una vida íntegra con la firme convicción de cumplir la voluntad de un Dios vivo y de que su alma se eleve al reino de los cielos (al modo de la escena de la pasión de Jesús en el Gólgota). Estas prácticas enseñan que la única forma de emanciparse de la tiranía de la muerte sería absorbiendo cualquier coacción externa en la propia voluntad o transformando el tener que morir en el poder querer morir. La vida no seria, por tanto, más que una gran escuela en la que no solo se aprende a vivir la vida, sino también el arte de acabarla ejemplarmente mediante un riguroso entrenamiento.

\section{Consideraciones finales}

A modo de conclusión, podemos afirmar que -para que una ética basada en el ejercitamiento constante sea modelo para la reflexión pedagógica actual- es preciso que los docentes se conviertan en verdaderos maestros: salgan del confort que da 
la costumbre y se catapulten a sí mismos desde su interior. Si hacen el proceso de operarse a sí mismos con un riguroso entrenamiento repetitivo que los lleve a la mejora de sí, con seguridad podrán llevar a los educandos a la conquista del monte de lo improbable, a animarlos en ese arduo camino que lleva al ser humano a enderezar la historia de su devenir histórico y encontrar su esencia.

Con ello se espera que se edifique un nuevo mundo: un mundo racionalmente organizado y estructurado, de tal manera que el hombre llegue a ser un verdadero atleta que normalice lo improbable en su cotidianidad y asuma al otro como un colaborador en su proyecto de perfeccionamiento y no como un obstáculo. Esta ética debe ser vinculante para que sea efectiva y el modelo tenga viabilidad. Esa es la labor que debe asumir el docente de hoy con base en las precedentes reflexiones, a fin de que la técnica no sea ya un arma de destrucción, sino que la paz sea garantizada y se eviten atrocidades como las que se presentaron en la imborrable y lamentable historia de la Europa contemporánea en los campos de concentración nazi, del que Auschwitz es un claro ejemplo.

Por todo ello, junto con el conflicto entre criadores del hombre que Nietzsche develó en el humanismo ilustrado, este asunto de la cria humana es, y debe de ser, uno de los temas más importantes que no se deben olvidar en la palestra política ni ética de las sociedades contemporáneas, por cuanto afecta indiscutiblemente el destino mismo de la humanidad. Vivimos en una época de profundos cambios, en los que la técnica y las antropotécnicas se imponen cada vez más, que demanda de nosotros asumir un rol activo en la selección, esto es, ponernos del lado del selector.

Queda mal, en una época en la que las circunstancias son favorables para ejercer el poder de elegir, no hacerlo y, en su lugar, continuar dejando esa loable labor a los otros, para de esta manera permitir que el hombre se siga imponiendo sobre el hombre mismo. Sloterdijk nos hace asi una invitación, que es más la postulación de una nueva ética, a existir no meramente como objeto de selección, sino como sujetos de ella, no de los otros sino de nosotros mismos, en el marco de una comunidad homeotécnica (2011, p. 215).

La sociedad post-epistolar ya no tendria entonces la marcada influencia religiosa y educativa de antes; pareciese como si los sabios y los dioses se hubieran retirado dejando al hombre solo ante sí mismo, desnudo como en sus orígenes, con la 
cuestión siempre imperiosa de qué hacer de su vida, en un horizonte biotecnológico abierto e incierto como el actual, pero que afortunadamente mantiene a aquél en igualdad de condiciones con los demás hombres. Cada hombre debe inventarse y narrarse a sí mismo y, al tener que elegir, estará simplemente eligiéndose a sí mismo.

De esta manera, Sloterdijk nos está llevando al terreno de las antropotécnicas, por medio de las cuales el hombre opera sobre sí mismo para mejora de sí. El adiestramiento y crianza no es ya entonces de unos hombres sobre otros, sino del individuo a partir de si mismo, cuyo fundamento está en las prácticas ascéticas de la Antigüedad. Como todo proceso de domesticación implica un fundamento ético, Sloterdijk lo encuentra en la postulación de una ética acrobática en un mundo homeotécnico, que desde la igualdad, la pluralidad y la libertad ha de contrarrestar las tendencias bélicas del ser humano. La historia ha puesto de relieve hasta dónde pueden llegar los alcances desbordados y monstruosos de dichas tendencias; por eso, Sloterdijk es fiel a la exigencia de pensar al hombre desde esa perspectiva conflictiva y desde una nueva mirada ética. 


\section{Referencias}

Agamben, G. (1998). Homo Saccer: El poder soberano y la vida nuda, I. (Trad. A. Gimeno). Valencia: Pre-textos.

Agamben, G. (2000). Homo Saccer: Lo que queda de Auschwitz. El archivo y el testigo, III. (Trad. A. Gimeno). Valencia: Pre-textos.

Castro, S. (2011). La educación como antropotécnica. Gubernamentalidad y Educación. Discusiones contemporáneas (pp. 9-15). Bogotá: IDEP.

Castro, S. (2012). Sobre el concepto de antropotécnica en Peter Sloterdijk. Revista de Estudios Sociales, (43), pp. 63-73.

Dewey, J. (2014). Naturaleza humana y conducta. Introducción a la psicología social. (Trad. R. Castillo). Ciudad de México: Fondo de Cultura Económica.

Flórez, R. y Vivas, M. (2007). La formación como principio y fin de la acción pedagógica. Educación y Pedagogía, 9(47), pp. 165-173.

Hobbes, T. (1992). Leviatán. O la materia, forma y poder de una República Eclesiástica y Civil. (Trad. M. Sánchez). Buenos Aires: Fondo de Cultura Económica.

Marín, D. (2017). Espiritualidad, ascesis y educación. O. Pulido, M. Suárez y O. Espinel (Comps.), Pensar de otro modo. Herramientas filosóficas para investigar en educación (pp. 51-67). Tunja: UPTC.

Nietzsche, F. (1993). Asi habló Zaratustra. (Trad. A. Sánchez). Barcelona: Ediciones Altaya.

Noguera-Ramírez, C. (2017). La formación como 'antropotécnica'. Aproximación al concepto de Peter Sloterdijk. Pedagogía y Saberes, (47), pp. 23-30.

Runge Peña,A. (2012). Laeducación comouna antropotécnica contra elsalvajizamiento 
humano: paradojas y complicaciones para el pensar pedagógico moderno. Educación y Pedagogía, 24(62), pp. 247-265.

Quintanas, A. (2009). Bioética, biopolíticas y antropotécnicas. Ágora, Papeles de filosofia, 2(28), pp. 157-168.

Sloterdijk, P. (2011). Sin salvación. Tras las huellas de Heidegger. (Trad. J. Chamorro). Madrid: Ediciones Akal.

Sloterdijk, P. (2012). Has de cambiar tu vida. Sobre antropotécnica. (Trad. P. Madrigal). Valencia: Pre-textos. 